\title{
On the Time-varying Linkages among the London Interbank Offer Rates for Major European Currencies
}

\author{
Go Tamakoshi \\ Graduate School of Economics, Kobe University \\ 2-1, Rokkodai, Nada-ku, Kobe 657-8501, Japan \\ E-mail: tamakosh@stu.kobe-u.ac.jp \\ Shigeyuki Hamori (Corresponding author) \\ Faculty of Economics, Kobe University \\ 2-1, Rokkodai, Nada-ku, Kobe 657-8501, Japan \\ E-mail: hamori@econ.kobe-u.ac.jp
}

Received: October 4, 2012

Accepted: October 25, 2012

Online Published: December 16, 2012

doi:10.5430/ijfr.v4n1p46

URL: http://dx.doi.org/10.5430/ijfr.v4n1p46

\begin{abstract}
We employ an asymmetric dynamic conditional correlation model to investigate the time-varying integration of the London Interbank Offered Rate (LIBOR) rates for three major European currencies -the euro (EUR), Swiss franc (CHF), and British pound (GBP). We assess the impacts of the global financial crisis and the European sovereign debt crisis on cross-currency dynamic correlations. Our findings suggest that the correlations are influenced more by negative innovations than by positive ones for the GBP-CHF and CHF-EUR pairs. While the global financial crisis increased the degree of interbank money market integration, the European debt crisis contrastingly decreased the dynamic correlations for each pair of LIBOR rates.
\end{abstract}

Keywords: Interbank money market, LIBOR, Asymmetric dynamic conditional correlation, European sovereign debt crisis, Global financial crisis

\section{Introduction}

The London Interbank Offered Rate (LIBOR), published by the British Bankers Association (BBA), is widely regarded as a benchmark for interbank lending. In fact, LIBOR is just an indicative rate (rather than a true transaction rate) reflecting the banks' beliefs about the rate at which they can borrow from other banks. The BBA LIBOR is also used as the basis for settling interest rate contracts on the world's major swaps, futures, and options exchanges. A rough estimate would indicate that a total of $\$ 150$ trillion of financial products worldwide are indexed to the LIBOR. Therefore, due to the substantial risk exposures of the banking businesses to changes in LIBOR rates, bank managers and monetary authorities are naturally interested in the movement of the rates for multiple currencies, particularly in view of the recent financial debt crises that badly affected the functioning of the interbank money markets. Despite the importance given to LIBOR, a surprisingly limited number of academic studies have analyzed the dynamics of the rates.

Recently, a few empirical studies touched upon the characteristics of the LIBOR time series (e.g., Krehbiel and Adkins, 2008, Kotomin et al., 2008, Hammoudeh et al., 2011). Krehbiel and Adkins (2008) find that Generalized Extreme Value distribution provides a good fit to capturing the exceedances of daily logarithmic differences in the US dollar LIBOR series. That is, when the initial LIBOR level is high, a certain level change is more likely to occur. Kotomin et al. (2008) contend that the preference for liquidity can provide one explanation as to why the LIBOR rates for the US dollar, the euro, Japanese Yen, Swiss Franc, and German Mark are higher before a year-end or quarter-end. Hammoudeh et al. (2011) provide evidence that the US dollar LIBOR and T-bill rates are asymmetrically co-integrated, suggesting different long-term co-movements to the threshold equilibrium during widening and narrowing down of the spreads between the two rates.

Another strand of research on LIBOR deals with the cross-currency causality between LIBOR spreads over the 
Overnight Indexed Swap (OIS), a swap contract with relatively secured lending costs but without the exchange of initial cash flows. The LIBOR-OIS spread, soaring since August 2007, is considered to measure the financial stress in interbank money markets. Both Imakubo et al. (2008) and Ji and In (2010), employing Vector-Autoregressive (VAR) models, obtain evidence of significant linear causality from the US dollar LIBOR-OIS spread to the spreads for other currencies during the global financial crisis period. Furthermore, Ji (2010), using a dynamic conditional correlation (DCC) model, identifies evidence of increased market integration of the US dollar LIBOR-OIS spread with those for the euro, British pound, and Australian dollar during the crisis period, primarily driven by the FX swap market liquidity.

A key objective of the present paper is to investigate the time-varying linkages of weekly data on 3-month LIBOR rates for the three main European currencies - the euro (EUR), British pound (GBP), and Swiss franc (CHF) - during the full sample period ranging from January 1999 to December 2011.

Our contributions to the literature on LIBOR are mainly two-fold. First, to our knowledge, we are the first to analyze the asymmetric behavior of time-varying correlations among the LIBOR rates for multiple currencies. To do so, we employ the asymmetric dynamic conditional correlation (A-DCC) model developed by Cappiello et al. (2006). This model is an extended version of the original DCC model first proposed by Engle (2002). One advantage of the DCC approach is that it captures the evolution of the time series co-movement directly. As the time-varying correlation is modeled together with volatility, we can identify the changes of integration over time, and the timing of the regime shifts endogenously. Cappiello et al. (2006) modified the DCC model, allowing for conditional asymmetries in covariance and correlation dynamics, and thus allowing us to investigate the existence of the asymmetric responses of conditional correlations to negative innovations.

Second, focusing on the dynamic linkages among the major European currencies, we assess the potential impacts of not only the global financial crisis but also the recent European sovereign debt crisis on the estimated dynamic conditional correlations. We pursue this using a method similar to that of Yiu et al. (2010), who model the DCC estimates using Autoregressive (AR) models, with dummy variables representing the crisis periods. Prior studies on the spread of the crises found evidence of significant increases in dynamic correlations in the stock, bond, and currency markets. The recent financial turmoil has been characterized by a credit crunch with interest rates on many kinds of borrowings getting higher. This must hold for the interbank loan markets as well. Thus, it is worth examining how the two financial crises mentioned above affected the dynamic cross-currency integration of LIBOR rates.

The rest of this paper is organized as follows. Section 2 explains the data used. Section 3 reports and discusses the empirical results. Finally, Section 4 presents our conclusions.

\section{Data}

We use weekly data on three-month maturity LIBOR rates for the three major European currencies, namely EUR, GBP, and CHF, for the period from January 1, 1999, when the euro was introduced, to December 31, 2011. Interestingly, throughout the period, the LIBOR rates generally exhibited a co-movement sign, except for one or two years after late 2009 (see Figure 1). The LIBOR rates are calculated and published by the British Bankers' Association. We extract all the data from Thomson Reuters Datastream. The use of weekly data enables us to avoid issues of contemporaneous trading. Weekly data are also less prone to noise than daily observations.

Table 1 presents the descriptive statistics for level and first-differences of each of the three LIBOR series. Note that Jarque-Bera tests reject normality for all the rates at the $1 \%$ significance level (Note 1). We check stationarity by conducting the Augmented Dickey-Fuller (ADF) unit root tests and find that all the series are I(1) variables (Note 2). Thus, we model all the LIBOR rates in the first-differences similar to previous studies.

\section{Results and Discussions}

We use the following three-step approach. Details on methodologies are described in Appendix 1.

\subsection{AR-EGARCH Specification}

Our first step consists of fitting the best of the univariate $\operatorname{AR}(k)-\operatorname{EGARCH}(p, q)$ models to each series of changes in LIBOR rates. Table 2 reports the estimated results of the AR-EGARCH models. We select EGARCH(1,1) models for all the LIBOR series. A notable finding is that the variance equations of each model exhibit a good fit to the data, empirically supporting our choice of the EGARCH models. In fact, all parameters in the equations are significant at the 5\% level, except for $\gamma_{1}$ of the EUR LIBOR rate. Moreover, the $p$-values of the Ljung-Box $Q$-statistics, $Q(20)$ and $Q^{2}(20)$, suggest that the null hypothesis of no autocorrelation for standardized residuals and standard residuals 
squared is accepted (Note 3 ).

\subsection{Asymmetric DCC Models}

The next step is to estimate the A-DCC models (Note 4) developed by Cappiello et al. (2006). Table 3 presents the empirical results. The estimates on the standardized residual $\left(a_{1}\right)$ parameters and that of the innovations in the conditional correlation matrix $\left(b_{1}\right)$ dynamics are statistically significant at the $1 \%$ level for all pairs of two LIBOR series. More interestingly, the estimates on the asymmetric term $\left(g_{1}\right)$ parameters are significant at the $1 \%$ level in the correlations for the CHF-EUR and GBP-CHF pairs. A significantly negative value of $g_{1}$ would indicate that the conditional correlations of the two LIBOR series are influenced more significantly by negative innovations (i.e., when the rates exhibit downward co-movement) than positive ones to changes of LIBOR rates. This finding may reflect how the LIBOR rates are computed institutionally, as Hammoudeh et al (2011) describe in detail. The LIBOR rates are in fact the indicative rates at which the panel banks believe they could borrow funds, and not the actual rates charged on transactions. The top quartile and bottom quartile of the banks' survey responses are deleted, and the middle two quartiles are averaged. This institutional setting may result in the observed asymmetric behaviors of the conditional correlations between the LIBOR pairs over time, because the rates quoted by the panel banks could co-move in different magnitudes, depending on whether the rates move upward (reflecting the concerns of banks facing high risk premium) or downward (indicating more optimistic views on the economy).

Figure 2 plots the paths of the estimated DCCs between each pair of the LIBOR rates. The DCC series indeed fluctuate significantly over the full sample period for all the pairs. The instability of the dynamic correlations may suggest the difficulty of risk management associated with the exposures of banking businesses to LIBOR rates. In Figure 2, the first vertical line indicates August 9, 2007, the onset of the Global financial crisis, while the second vertical line corresponds to December 16, 2009, the beginning of the European debt crisis. Through these two crises, the time-varying correlations exhibit quite different patterns across the pairs. As for the CHF-EUR pair, for which there are strong linkages in those interbank markets, we find no particular increases in the DCC estimates during the two crisis periods, except for the abrupt peak around July 2011. In contrast, the correlations for the EUR-GBP and GBP-CHF pairs are evidently higher during the Global financial crisis period. Moreover, for these two pairs, the European sovereign debt crisis seems to lower the time-varying correlations more than in the pre-crisis periods. Given such evidence of structural breaks for the DCCs, we are motivated to examine quantitatively the impacts of the two crises by modeling the estimated dynamic correlations using dummy variables, which we explain in detail next.

\subsection{AR Models for Estimated DCCs with Crisis Dummies}

Our last step is to employ AR (1) models with two dummy variables, one for the global financial crisis and the other for the European sovereign debt crisis, to capture the evolution of the estimated DCCs. Table 4 shows the estimation results. The constant terms $\left(\delta_{1}\right)$ are significant at the $5 \%$ level. The coefficients of the AR terms $\left(\delta_{1}\right)$ are also significant for all the three pairs at the $1 \%$ level, taking their values close to unity. This indicates a strong persistence in the time-varying correlations among the LIBOR rates. Relatively high values of adjusted $R^{2}$ indicate that the regression models are sensibly selected.

With respect to the coefficients of the crisis dummies ( $\xi_{1}$ and $\xi_{2}$ ), we point out two noteworthy observations. First, the coefficients of the global financial crisis dummy $\left(\xi_{1}\right)$ are positively significant at the $5 \%$ level for both the EUR-GBP and GBP-CHF pairs. This seems reasonable, because the Global financial crisis, whose magnitude was unanticipated, may have caused direct shocks on the interbank money markets in various European nations, triggering regime shifts in the integration rather uniformly. This is generally in line with Ji (2010), who finds increased dynamic conditional correlations among the LIBOR-OIS spreads for various currencies, including the euro, US dollar, British pound, and the Australian dollar, during the 2007-2009 crisis. Second, all the coefficients of the European sovereign debt crisis dummy $\left(\xi_{2}\right)$ are negative, while only the coefficient of the GBP-CHF pair is statistically significant. As Figure 1 indicates, while the EUR and GBP LIBOR rates soared after the onset of the debt crisis, the CHF LIBOR rate stayed flat or even declined. One possible reason for this could be that the debt crisis affected the money markets non-uniformly, reflecting different degrees of vulnerability to the credit crunches caused 
by the crisis. That is, the banks in the Euro zone (and the UK as well), who had substantial exposures to direct Greek sovereign debt holdings, may have been most severely affected by the crisis, while the Swiss banks, who had little exposure, could be insulated from the dislocation of the interbank money markets. We can intuitively contend that the decreasing DCCs among the LIBOR rates after the debt crisis reflect the differences of the banks' exposures to the root cause of the crisis - the solvency issue of the Greek debts held by the banks.

\section{Conclusions}

Utilizing the asymmetric dynamic conditional correlation technique, this paper investigates the dynamic integration of 3-month LIBOR rates for three major European currencies, the EUR, CHF, and GBP. The sample period ranges from January 1999 to December 2011. We model the estimated dynamic correlations using AR models with two crisis dummy variables, one signifying the 2007-2009 global financial crisis period, and the other signifying the recent European sovereign debt crisis period.

Our analysis yields the following four main findings: (i) We find evidence of asymmetric dynamic conditional correlations for the GBP-CHF and CHF-EUR pairs, suggesting that the correlations are influenced more by joint negative innovations than positive ones. Such asymmetric behaviors indicate how the LIBOR rates are determined institutionally, reflecting the panel banks' indicative rates. (ii) The dynamic correlations for all the pairs substantially fluctuate over time, implying the difficulties banks face in managing the risks of their LIBOR rate exposures. (iii) Generating a financial shock across Europe, the global financial crisis increased the integration of interbank money markets, as reflected in the soaring DCC estimates for both of the EUR-GBP and GBP-CHF pairs. (iv) In contrast, the coefficients of the European sovereign debt crisis dummy are predominantly negative (although significant only for the GBP-CHF pair), represented by its decreased correlation after the onset of the crisis. Our results are especially relevant for the bank managers and policy makers in the European countries who are concerned with managing the risks associated with LIBOR rate movements and its dynamic linkages across the various interbank markets.

\section{Acknowledgement}

We are grateful to two anonymous referees for helpful comments and suggestions.

\section{References}

Cappiello, L., Engle, R., \& Sheppard, K. (2006). Asymmetric dynamics in the correlations of global equity and bond returns. Journal of Financial Econometrics, 4, 557-572. http://dx.doi.org/10.1093/jjfinec/nbl005

Engle, R. (2002). Dynamic conditional correlation: a simple class of multivariate generalized autoregressive conditional heteroskedasticity models. Journal of Business and Economic Statistics, 20, 339-350. http://dx.doi.org/10.1198/073500102288618487

Hammoudeh, S., Chen, L-H., \& Yuan, Y. (2011). Asymmetric convergence and risk shift in the TED spreads. North American Journal of Economics and Finance, 22, 277-297. http://dx.doi.org/10.1016/j.najef.2011.05.001

Imakubo, K., Kimura, T., \& Nagano, T. (2008). Cross-currency transmission of money market tensions. Bank of Japan Review, E-2. [Online] Available: https://www2.boj.or.jp/en/research/wps_rev/rev_2008/data/rev08e02.pdf

Jarque, C. M., \& Bera, A. K. (1987). Test for normality of observations and regression residuals. International Statistical Review, 55, 163-172. [Online] Available: http://www.jstor.org/stable/10.2307/1403192

Ji, P. I. (2012). Time-varying financial stress linkages: evidence from the LIBOR-OIS spreads. Journal of International Financial Markets, Institutions \& Money, 22, 647-657. http://dx.doi.org/10.1016/j.intfin.2012.04.001

Ji, P. I., \& In, F. (2010). The impact of the global financial crisis on the cross-currency linkage of LIBOR-OIS spreads. Journal of International Financial Markets, Institutions \& Money, 20, 575-589. http://dx.doi.org/10.1016/j.intfin.2010.07.005

Kotomin, V., Smith, S. D., \& Winters, D. B. (2008). Preferred habitat for liquidity in international short-term interest rates. Journal of Banking \& Finance, 32, 240-250. http://dx.doi.org/10.1016/j.jbankfin.2007.03.007

Krehbiel, T., \& Adkins, L. C. (2008). Extreme daily changes in U.S. Dollar London inter-bank offer rates. International Review of Economics and Finance, 17, 397-411. http://dx.doi.org/10.1016/j.iref.2006.08.009

Ljung, G., \& Box, G. (1978). On a measure of lack of fit in time series models. Biometrika, 66, 265-270. [Online] Available: http://www.jstor.org/stable/2335207 
Nelson, D. (1991). Conditional heteroskedasticity in asset returns: a new approach. Econometrica, 59, 347-370. [Online] Available: http://www.jstor.org/stable/2938260

Tamakoshi, G., \& Hamori, S. (2012). An asymmetric dynamic conditional correlation analysis of linkages of European financial institutions during the Greek sovereign debt crisis. European Journal of Finance, (forthcoming). http://dx.doi.org/10.1080/1351847X.2012.712921

Toyoshima, Y., Tamakoshi, G., \& Hamori, S. (2012). Asymmetric dynamics in correlations of treasury and swap markets: Evidence from the US market. Journal of International Financial Markets, Institutions \& Money, 22, 381-394. http://dx.doi.org/10.1016/j.intfin.2011.12.002

Yiu, M. S., Ho, W. A., \& Choi D. F. (2010). Dynamic correlation analysis of financial contagion in Asian markets in global financial turmoil. Applied Financial Economics, 20, 345-354. http://dx.doi.org/10.1080/09603100903494946

\section{Notes}

Note 1. See Jarque and Bera (1987).

Note 2. The results of the unit root tests are available upon request.

Note 3. See Ljung and Box (1978).

Note 4. As for examples of previous studies using the A-DCC models, see Tamakoshi and Hamori (2012) and Toyoshima et al. (2012)

Note 5. See Nelson (1991) for the EGARCH model.

Note 6. We selected August 9, 2007, as the beginning of the 2007-2009 global financial crisis, when BNP Paribas suspended its funds affected by the U.S. subprime mortgage liabilities. With regard to the onset of the European debt crisis, we chose December 16, 2009, when Standard \& Poor's cut Greece's credit rating from A1- to BBB+, triggering concerns over the country's sovereign debt issues.

\section{Appendix 1}

In this article, we analyze the asymmetric dynamic conditional correlations of the 3-month LIBOR rates for the three major European currencies (EUR, GBP, and CHF), taking the following three-step procedure. In the first step, we estimate the conditional variances for each LIBOR, employing univariate autoregressive-exponential generalized autoregressive conditional heteroskedasticity $(\operatorname{AR}(k)-\operatorname{EGARCH}(p, q))$ models (Note 5) as follows. We represent the conditional mean as

$$
r_{t}=\varphi_{0}+\sum_{i=1}^{k} \varphi_{i} r_{t-i}+\varepsilon_{t}, \quad \varepsilon_{t} \mid I_{t-1} \sim N\left(0, H_{t}\right)
$$

Where $r_{t}=\left[r_{1 t}, r_{2 t}\right]^{\prime}$ is a $2 \times 1$ vector including first-differences of each LIBOR series and $\varepsilon_{t}=\left[\varepsilon_{1 t}, \varepsilon_{2 t}\right]^{\prime}$ is a $2 \mathrm{x}$ 1 vector of innovations conditional on the information set at time $\mathrm{t}-1$; we employ the Schwartz-Bayesian information criterion (SBIC) to determine the optimal lag length $k$. We define the conditional variance-covariance matrix as

$$
H_{t}=E\left[\varepsilon_{t} \varepsilon_{t}^{\prime}\right]=D_{t} C_{t} D_{t}
$$

where the diagonal matrix $D_{t}$ is the conditional SD obtained from Eq. (1) with $\sigma_{i, t}$ on the $i$-th diagonal and $C_{t}$ is a symmetric conditional correlation matrix. The element in $D_{t}$ follows the EGARCH specification given by

$$
\log \left(\sigma_{i, t}^{2}\right)=\omega+\sum_{i=1}^{q}\left(\alpha_{i}\left|z_{i, t-i}\right|+\gamma_{i} z_{i, t-i}\right)+\sum_{i=1}^{p} \beta_{i} \log \left(\sigma_{i, t-i}^{2}\right)
$$

where $z_{i, t}=\varepsilon_{i, t} / \sigma_{i, t}$ has a normal distribution with zero mean and unit variance and SBIC is used to select the optimal lag lengths $p$ and $q$. We assume that the random variable $z_{i, t}$ has a generalized error distribution (GED); its density function is shown as follows: 


$$
f(x)=\frac{v}{2^{[(v+1) / v]} \Gamma(1 / v) \lambda} \exp \left(-\frac{1}{2}\left|\frac{x}{\lambda}\right|^{v}\right), \quad \lambda=\sqrt{\frac{2^{(-2 / v)} \Gamma(1 / v)}{\Gamma(3 / v)}} .
$$

The logarithm form of the EGARCH models ensures nonnegativity of the conditional variance without having to constrain the coefficients of the model. Furthermore, we can also capture the asymmetric effects of positive and negative innovations by including the term $z_{t-i}$. Unlike the GARCH models, EGARCH specifications allow for the possibility of a cyclical behavior in volatility, because negative coefficients are not precluded.

Now that we obtain conditional variance from Eq. (2), our second step is to analyze the conditional correlations using the A-DCC model developed by Cappiello et al. (2006). The asymmetric generalized dynamic conditional correlation (AG-DCC) model is given by

$$
Q_{t}=\left(\bar{Q}-A^{\prime} \bar{Q} A-B^{\prime} \bar{Q} B-G^{\prime} \bar{N} G\right) \bar{P}+A^{\prime} z_{t-1} z_{t-1}^{\prime} A+G^{\prime} \eta_{t-1} \eta_{t-1}^{\prime} G+B^{\prime} Q_{t-1} B
$$

where $\bar{Q}$ and $\bar{N}$ are the unconditional correlation matrices of $z_{t}$ and $\eta_{t}$. The negative standardized residuals for asymmetric impacts $\eta_{t}$ are defined as $\eta_{t}=I\left[z_{t}<0\right] \circ z_{t}$, where $I[\cdot]$ is an indicator function taking the value of 1 if the argument is true and 0 otherwise, and "०" indicates a Hadamard product. The A-DCC (1,1) model can be regarded as a special case of the above AG-DCC $(1,1)$ model if the matrices A, B, and G are replaced by scalars $\left(a_{1}\right.$, $b_{1}$, and $\left.g_{1}\right)$. Since it can be shown that $Q_{t}$ is positive definite with a probability of 1 if $\left(\bar{Q}-A^{\prime} \bar{Q} A-B^{\prime} \bar{Q} B-G^{\prime} \bar{N} G\right)$ is positive definite, we can compute the correlation matrix using the following formula:

$$
P_{t}=Q_{t}^{*-1} Q_{t} Q_{t}^{*-1}
$$

where $Q_{t}^{*}$ is a diagonal matrix with the square root of the $i$-th diagonal element of $Q_{t}$ on its $i$-th diagonal position.

Our third step is to apply AR (1) models to model the conditional correlations obtained from the second step. Here, we include the two crisis dummy variables, Crisis ${ }_{1 t}$ (1 if $\mathrm{t}=2007 / 8 / 8, \ldots, 2009 / 12 / 15 ; 0$ otherwise $)$ and Crisis $_{2 t}$ ( 1 if $\mathrm{t}=2009 / 12 / 16, \ldots, 2011 / 12 / 31 ; 0$ otherwise), representing the 2007-2009 global financial crisis period and the recent European sovereign debt crisis period, respectively (Note 6). This specification enables us to test whether each of the crises significantly changed the dynamics of the estimated conditional correlations among the LIBOR series investigated; that is,

$$
\hat{D C C}_{t}=\delta_{0}+\delta_{1} \hat{D C C}_{t-1}+\xi_{1} \text { Crisis }_{1 t}+\xi_{2} \text { Crisis }_{2 t}+\delta_{t}
$$

\begin{tabular}{|c|c|c|c|c|c|}
\hline & Mean (percentage) & Std Dev. & Skewness & Kurtosis & Jarque-Bera \\
\hline \multicolumn{6}{|c|}{ Level data } \\
\hline Euro & 2.834 & 1.310 & 0.035 & 1.963 & 30.580 \\
\hline GBP & 4.085 & 1.896 & -0.793 & 2.265 & 86.444 \\
\hline $\mathrm{CHF}$ & 1.345 & 1.109 & 0.573 & 1.900 & 71.366 \\
\hline \multicolumn{6}{|c|}{ First-differenced data } \\
\hline Euro & -0.003 & 0.062 & -1.188 & 17.275 & $5,915.910$ \\
\hline GBP & -0.008 & 0.086 & -6.007 & 93.475 & $235,322.800$ \\
\hline $\mathrm{CHF}$ & -0.002 & 0.074 & -0.499 & 42.616 & $44,363.780$ \\
\hline
\end{tabular}

Table 1. Descritive statistics

Note: The sample covers the period between January 1, 1999 and December 31, 2011 for a total of 679 weekly observations. 
Table 2. Empirical results of AR-EGARCH models

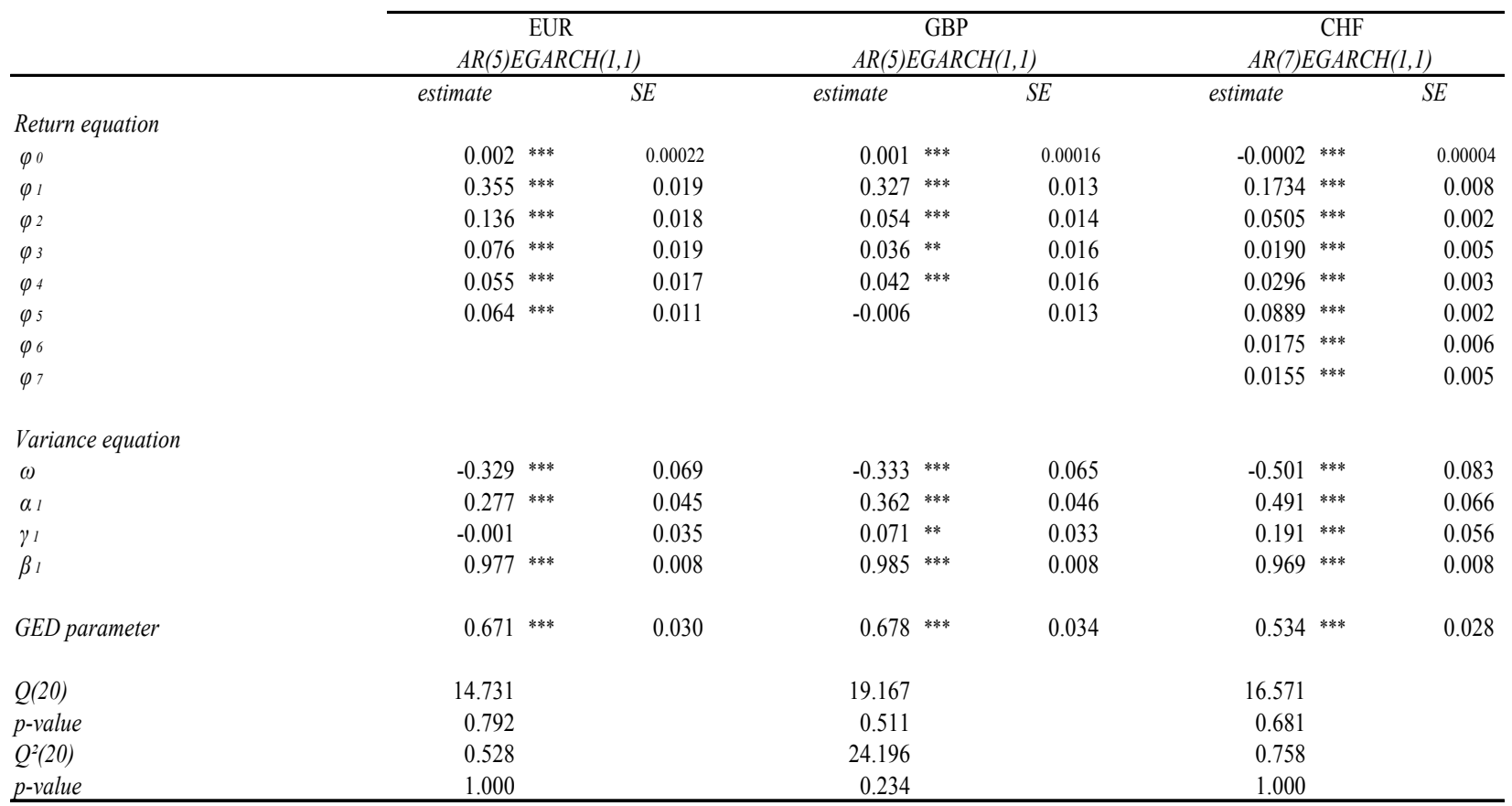

Notes: ${ }^{* * *},{ }^{* *}$, and $*$ indicate statistical significance at the $1 \%, 5 \%$, and $10 \%$ level, respectively.

$Q(20)$ and $Q^{2}(20)$ are Ljung-Box statistics up to the 20th orders in standardized residuals and standardized residuals squared, respectively.

Table 3. Dynamic conditional correlation (DCC) estimates of the LIBORs

\begin{tabular}{|c|c|c|c|c|c|c|}
\hline \multirow[t]{2}{*}{ Coefficients } & \multicolumn{2}{|c|}{ EUR vs. GBP } & \multicolumn{2}{|c|}{ GBP vs. CHF } & \multicolumn{2}{|c|}{ CHF vs. EUR } \\
\hline & estimate & $S E$ & estimate & SE & estimate & $S E$ \\
\hline$a_{1}$ & $0.027^{* * *}$ & 0.008 & $0.014^{* * *}$ & 0.003 & $0.006^{* * *}$ & 0.002 \\
\hline$b_{1}$ & $0.920^{* * *}$ & 0.025 & $0.984^{* * *}$ & 0.005 & $0.988^{* * *}$ & 0.005 \\
\hline$g_{I}$ & 0.017 & 0.021 & $-0.015^{* * *}$ & 0.003 & $-0.011^{* * *}$ & 0.002 \\
\hline Log likelihood & -1126.2 & & -1092.5 & & -1209.1 & \\
\hline
\end{tabular}

Note: $* * * * *$, and $*$ indicate statistical significance at the $1 \%, 5 \%$, and $10 \%$ level, respectively.

Table 4. AR models with crisis dummy variables for the estimated DCC coefficients

\begin{tabular}{|c|c|c|c|c|c|c|}
\hline \multirow[t]{2}{*}{ Coefficients } & \multicolumn{2}{|c|}{ EURvs. GBP } & \multicolumn{2}{|c|}{ GBP vs. CHF } & \multicolumn{2}{|c|}{ CHF vs. EUR } \\
\hline & estimate & p-value & estimate & p-value & estimate & p-value \\
\hline$\delta_{0}$ & $0.017^{* * *}$ & 0.004 & $0.003^{* *}$ & 0.001 & $0.024 * * *$ & 0.006 \\
\hline$\delta_{l}$ & $0.949 * * *$ & 0.012 & $0.978 * * *$ & 0.007 & $0.945^{* * *}$ & 0.013 \\
\hline$\xi_{1}$ & $0.009 * *$ & 0.004 & $0.005 * *$ & 0.003 & -0.002 & 0.004 \\
\hline$\xi_{2}$ & -0.004 & 0.003 & $-0.005^{* *}$ & 0.002 & -0.006 & 0.004 \\
\hline Adjusted R2 & 0.929 & & 0.980 & & 0.904 & \\
\hline
\end{tabular}

Note: ${ }^{* * *},{ }^{* *}$, and $*$ indicate statistical significance at the $1 \%, 5 \%$, and $10 \%$ level, respectively. 


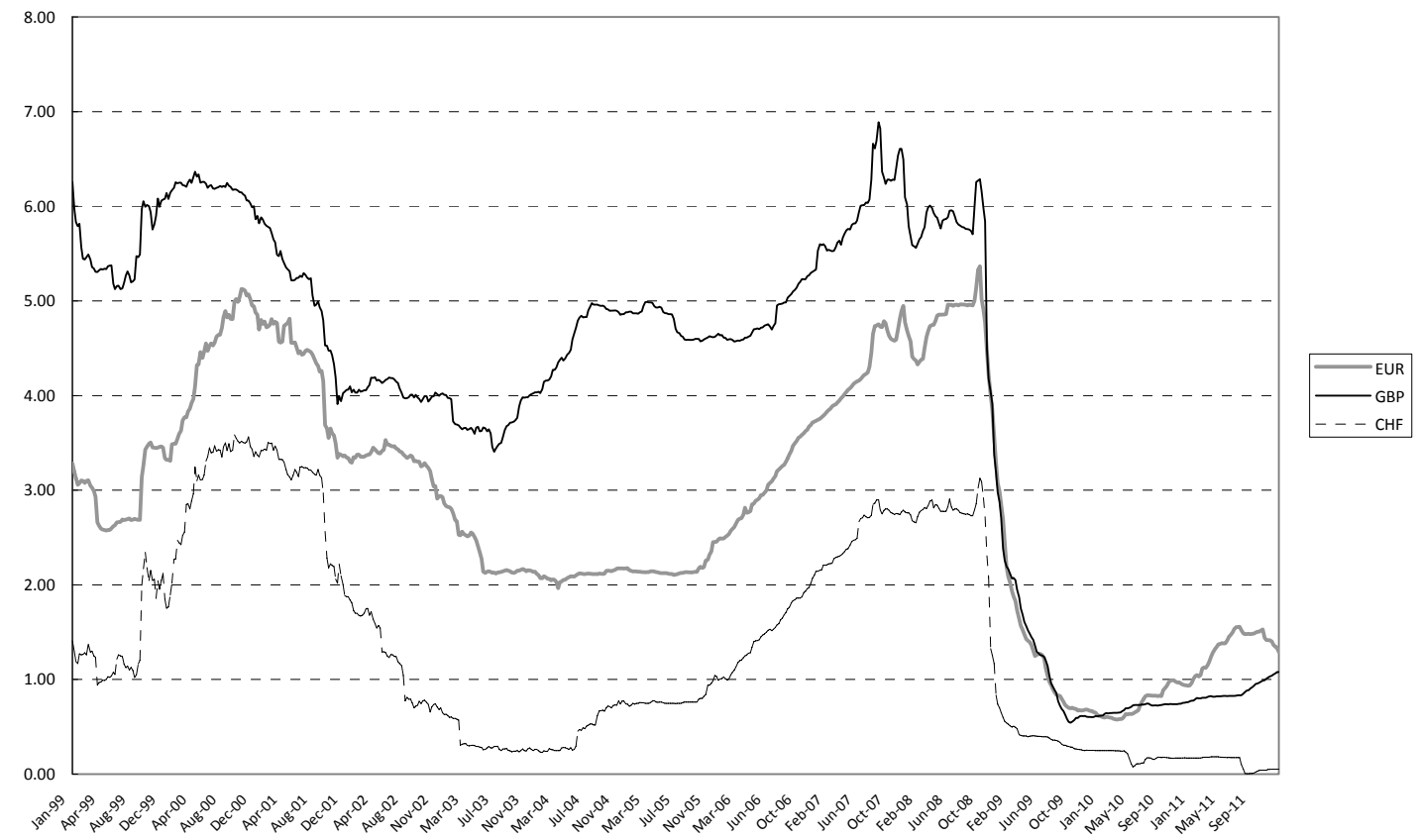

Figure 1. Historical paths on the 3-month LIBOR for three European currencies (in percentage)

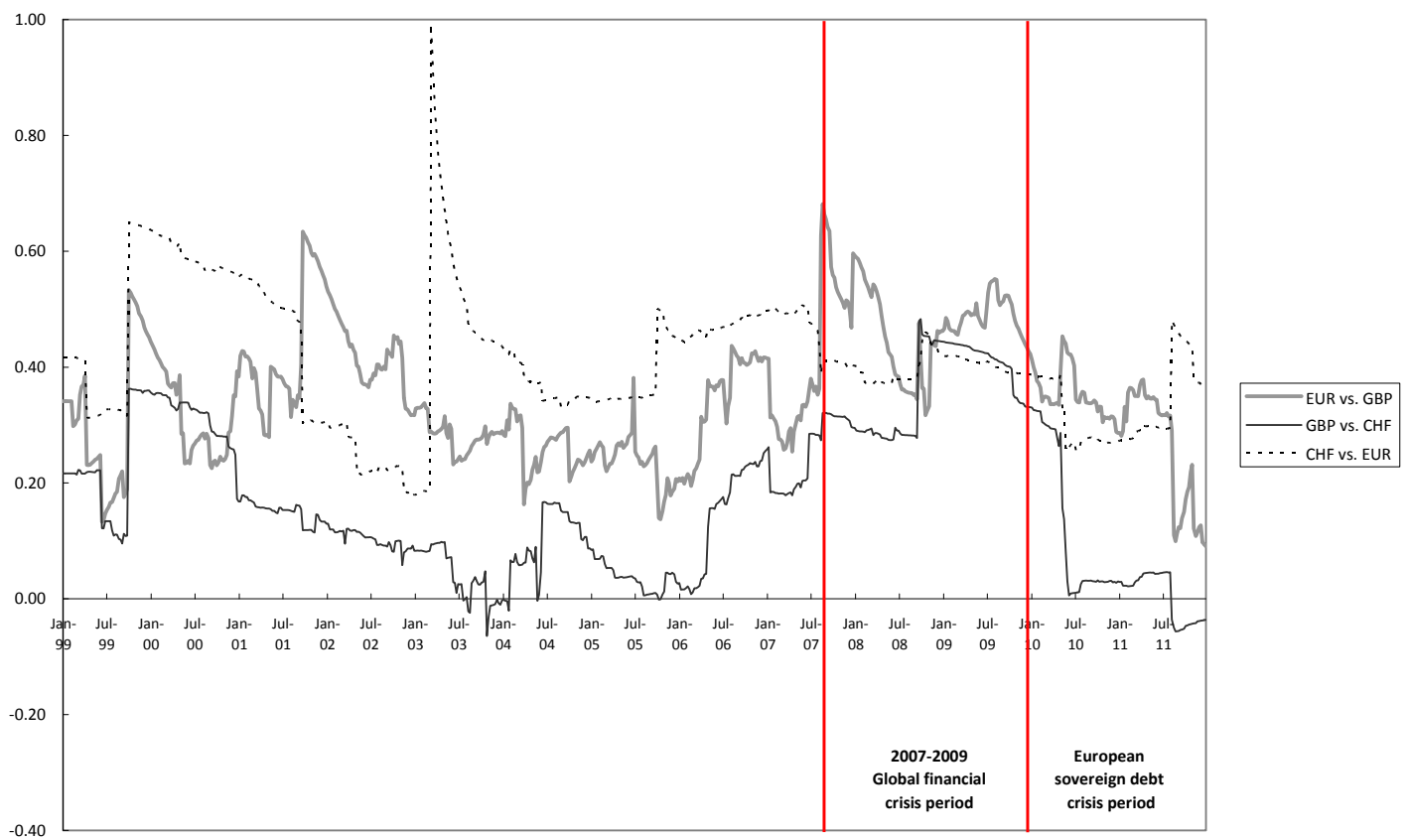

Figure 2. Dynamic conditional correlation between the LIBOR rates 